\title{
Road Pavement Information Modeling through Maintenance Scenario Evaluation
}

\author{
C. Oreto $\mathbb{D}^{1},{ }^{1}$ S. A. Biancardo ${ }^{D},{ }^{1}$ N. Viscione $\mathbb{D},{ }^{1}$ R. Veropalumbo $\mathbb{D},{ }^{1}$ and F. Russo $\mathbb{D}{ }^{1,2}$ \\ ${ }^{1}$ Department of Civil, Construction and Environmental Engineering, Federico II University of Naples, 80125 Naples, Italy \\ ${ }^{2}$ La.S.Tra-Laboratory of Road Materials, Federico II University of Naples, 80125 Naples, Italy
}

Correspondence should be addressed to S. A. Biancardo; salvatoreantonio.biancardo@unina.it

Received 21 August 2020; Accepted 10 May 2021; Published 24 May 2021

Academic Editor: Stefano de Luca

Copyright $(2021$ C. Oreto et al. This is an open access article distributed under the Creative Commons Attribution License, which permits unrestricted use, distribution, and reproduction in any medium, provided the original work is properly cited.

Road maintenance operations involve the preservation of the optimal functionality of the pavement. Sometimes the rehabilitation of the pavement layout does not have long lasting effects due to a lack of compliance with the constraints imposed by the technical specifications for the design of materials. The purpose of this paper is to present an efficient BIM tool to help in road maintenance operations through the management of data arising from laboratory testing of road pavement bituminous materials required for the quality control of mixtures. The database associated to the BIM model is a collection of three years of data derived from laboratory investigation on bituminous mixtures' samples adopted for the maintenance of four main roads located in southern Italy. An algorithm that interacts with the three-dimensional road model has been implemented in order to give road administrations an easy-to-read alert signal for the road pavement structure of the road network that may present the most critical conditions due to poor mechanical and physical features.

\section{Introduction}

The main goal in developing a road pavement structure is to ensure its ability to withstand high loads from traffic without excessive deterioration of the structural and surface characteristics that could compromise driving safety and comfort throughout its service life.

The most effective way to achieve this goal is planning maintenance operations based on specific performance indicators that help maintain appropriate efficiency and functionality.

These performance indicators, namely, Pavement Condition Index (PCI) and Present Serviceability Index (PSI), are used to rate the state of the road pavement based on road surface conditions and distress [1].

The deterioration rate of road performance indicators depends on a number of factors, including traffic loads, pavement layer thicknesses, materials, subgrade bearing capacity, environmental conditions, construction techniques, and construction quality [2].
In particular, for a flexible pavement, it has been demonstrated that the percentage air voids of a bituminous mixture play a fundamental role both in rutting and fatigue cracking resistance [3], as well as its thermal behavior and resistance to freeze-thaw cycles [4].

Moreover, researchers and administrations widely use Marshall test results to evaluate rutting resistance of the asphalt pavement in high temperature $[5,6]$.

However, the combination of physical and mechanical features of a bituminous mixture primarily depends on its composition, in terms of aggregate size distribution, bitumen content, and properties of both aggregates and bitumen. For instance, given the aggregate size distribution, the optimum bitumen content allows for the creation of a thin bitumen film on the aggregate's surface, maximizing the mixture's ability to carry loads and minimizing its viscous flow $[7,8]$.

Indeed, physical and mechanical features such as bitumen content, air voids, and Marshall Stability have a lower reliability in the performance prediction under dynamic and 
repeated loads than specific performance indicators, namely, roughness and skid resistance, which have a direct relationship with the evolution of distress over time.

The idea of considering the basic physical and mechanical features of bituminous mixtures for the prediction of the service life arises from the necessity of exploiting all the scarce available data to optimize routine maintenance operations and establish a clear prioritization of the road sections under examination when the monitoring of any other condition indicator is not foreseen.

Moreover, when the bearing capacity of the unbounded layers is high enough to exclude numerous complex and interconnected phenomena (i.e., cracking, rutting, pumping, and permanent deformation) that can cause failure of the pavement, it can be legitimate to reduce the analysis to few basic variables that have a high influence on the deterioration of the surface layer.

The totality of this information and its time evolution help assess the current state of a road pavement, and this information must be considered while planning road maintenance and management operations.

In the last few years, researchers have been focusing their attention on assessing the benefits of using digital tools and processes to support the entire life of transportation facilities and road infrastructures, from strategic planning, design, and construction [9-17] to performance management and maintenance [18-20].

Even though BIM processes applied to infrastructure facilities have not yet reached an adequate level of maturity, Leone et al. [21] managed to meet all the design requirements as well as the expected technical specifications of a railway facility project. The BIM application proved to be effective in overcoming procedural delays due to design error and allowed the designer to control costs and timing throughout the whole process.

As highlighted by Sankaran et al. [22] in their review, among the most productive uses of Civil Integrated Management in the road field is the automation of construction activities such as excavation, grading, milling, and paving, but also the possibility of collecting and updating as-built data for creating a digital archive of information to facilitate management and future project development.

Tang et al. $[23,24]$ used the visual programming software Dynamo $@$ for Revit $\AA$ to support the design process through the implementation of an empirical model for the analysis of permanent deformation of the asphalt pavement, which allows users to select the pavement that best suits the desired service life.

Bazlamit et al. [25] developed a Geographic Information System-based map of the paved areas of Al-Zaytoonah University (Jordan) that also contained a comprehensive database of information, including the field survey results in terms of PCI. The integrated model was intended to support the administration to rationally plan maintenance and rehabilitation of the paved network.

Chen et al. [26] used the same technology to predict maintenance costs based on the amount of distress detected on the road pavement and evaluated the effectiveness of maintenance operations in terms of time between the treatment and the appearance of new damage.

Heikkilä et al. [27] applied BIM to the process of road maintenance by combining the model of the existing road structure with the $3 \mathrm{D}$ point cloud of the road surface unevenness to achieve cost optimization of the rehabilitation works and continuous control of the milling and paving machines during the operations.

Cost optimization of the maintenance works was also the main focus of Bae et al. [28], who used BIM technique to develop a model capable of optimizing milling and overlay quantities of hot bituminous mixtures and improving the final result of the construction process by simulating all the possible combinations of surface layer geometry and irregularities of the pavement substructure.

The developed BIM process reduced the cost of construction by $12 \%$. Despite the increasing interest in the topic, one of the main challenges of using BIM in infrastructure management, as pointed out by Costin et al. [29] in their review, is developing methods that can help in prioritizing operation and maintenance tasks, taking into consideration a limited available budget.

In order to provide adequate maintenance of the road network, ordinary and extraordinary maintenance works of Italian roads are carried out by the prescriptive control activities as indicated in the technical specifications for Italian road works. During the road maintenance operations and at each stage of the work, the project management carries out all the necessary tests, verification, and checks to comply with the qualitative and quantitative standards imposed by the contractual requirements [30].

In the work under consideration, the road network BIM model was intended as a repository of information regarding the road pavement materials' properties resulting from the maintenance operations on four main roads located in the province of Caserta, Italy.

The database associated with the BIM model was created by compiling information on the properties of surface materials in terms of bitumen content, air voids (determined by dimensional, sealed specimen, and Saturated Surface Dry specimen procedures), and Marshall Stability by means of a laboratory investigation of the mixtures' samples collected during routine maintenance works for a time period spanning from 2011 to 2013, while checking whether the requirements have been met in the preparation of the mixture and in the laying.

In order to utilize the aforementioned information to aid in the operations and maintenance phases throughout the whole life cycle of the infrastructure, Dynamo $®$ software was adopted to integrate a specific model with a prioritizing algorithm based on bituminous mixtures' performances, with the ability to identify sections in need of maintenance.

\section{Aims and Methods}

The aim is to develop an efficient BIM tool that can assist road pavement maintenance operations through data management arising from laboratory testing on bituminous materials. 
First, as shown in Figure 1, the roads under investigation were selected, and then, in the La Stra road pavements' laboratory of Federico II University of Naples, an investigation of the wearing courses' properties was carried out in order to evaluate soluble binder content as well as Marshall Stability and air voids.

Second, the investigated roads were modelled using BIM-based tools, and then, the ranking algorithm was developed and applied for graphical output and other considerations.

2.1. Data Collection. For the purpose of this study, four main roads (SP290, SP333, SP335, and SP336) located in the Province of Caserta, Italy, were selected (see Figure 2).

Routine maintenance operations have been performed on the analyzed road sections on lightly distressed pavements, presenting a widespread loss of superficial texture and raveling of coarse aggregates and causing a reduction of surface roughness and driving safety. No fatigue cracking, rutting, or any bearing capacity failure of the unbounded layers were detected at the time of routine maintenance operations.

For different sections and for each wearing course, a bituminous mixture sample was taken, in order to determine, in the La Stra road pavements laboratory, the properties of the mixtures in terms of bitumen content, percentage air voids (dimensional, SSD, and sealed specimen procedures), and Marshall Stability.

The bituminous mixtures' samples were collected after each routine maintenance operation to assess the compliance of the physical and mechanical features of the materials with the local technical specifications for road works. Whenever the road pavement materials did not comply with the technical thresholds, an economic deduction was applied to the road works because the pavement probably would have failed to guarantee its predicted service life.

The mix compositions of the wearing courses were obtained through the optimization of the main properties of the bituminous mixtures in compliance with the mechanical performances required by the technical specifications [31] under examination.

The aggregate size distribution of the bituminous mixtures and the limits imposed by the technical specifications are reported in Figure 3.

Limestone and Basaltic aggregates were adopted for the construction of the lithic skeleton, while a neat bitumen 50/70 produced in an Italian oil refinery was used as binder.

The test method for determining the binder content of a test portion of the bituminous mixture comprises the following operations, as stated in UN EN 12697-1 [32]: (a) binder extraction by dissolving in a hot solvent; (b) separation of mineral matter from the binder solution; (c) determination of binder quantity by difference of binder recovery; (d) calculation of soluble binder content.

In order to carry out tests on compacted specimens, a Marshall impact compactor was adopted according to UNI EN 12697-30 [33].
The Marshall Stability test was carried out on the obtained cylindrical specimens. The test was performed according to UNI EN 12697-34 [34]. The maximum attained load represents the stability of the bituminous mixture.

The air voids' content of the bituminous specimen derived from Marshall compaction is calculated as reported in UNI EN 12697-8 [35] with the following equation:

$$
V_{m}=\frac{\rho_{m}-\rho_{b}}{\rho_{m}} \cdot 100
$$

where $V_{m}$ is the air voids' content of the mixture (\%), $\rho_{m}$ is the maximum density of the mixture $\left(\mathrm{kg} / \mathrm{m}^{3}\right)$, and $\rho_{b}$ is the bulk density of the specimen $\left(\mathrm{kg} / \mathrm{m}^{3}\right)$.

The maximum density of the mixture is calculated according to UNI EN 12697-5 [36], while the bulk density of the specimen is determined by following the proposed procedures as reported in UNI EN 12697-6 [37]:

(1) Dimensional bulk density

(2) Sealed specimen bulk density

(3) Saturated Surface Dry (SSD) bulk density

Table 1 shows an excerpt of the laboratory results for the four investigated roads in terms of bitumen content, air voids' percentage, and Marshall Stability.

2.2. BIM Road Modeling. In order to facilitate modeling and efficiency on file management, cartography and roads were matched with the same coordinate system to establish a correct topographical relationship.

The three-dimensional surface of the ground for the case study was obtained using Autodesk Infraworks $®$ tool (see Figure 4).

Then, road axis modeling and its parametric road section were performed based on the cooperation of BIM software such as Revit $\AA$, Civil $3 \mathrm{D} \cap$, and Infraworks $\AA$.

Once the roads' boundaries were defined, the layout was exported to Civil $3 \mathrm{D} \cap$ (see Figure 5(a)) to create the road axis to be imported in $\operatorname{Revit} \circledast$, in which the road section was parameterized.

Figure 5(b) reports the appearance of the topography and the planimetric view of one of the road sections under

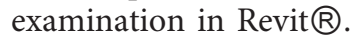

The parametric road section was constructed based on the pavement structure of the roads under examination, i.e., a flexible pavement composed of wearing course, binder, and base layer made of hot bituminous mixtures and an unbound granular subbase made of graded crushed rock and placed on the subgrade (see Figure 6).

The cross section of the examined roads is a single twoway carriageway with one lane in each direction. In this

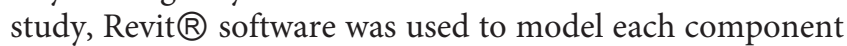
of the road section by customizing each existing family. The $3 \mathrm{D}$ visual parametric model gives an intuitive sense and understanding of the totality of the design and also clearly displays the advantages and disadvantages of the design from a practical perspective, which helps in decision-making for engineers. Through parametric modeling of the asphalt 

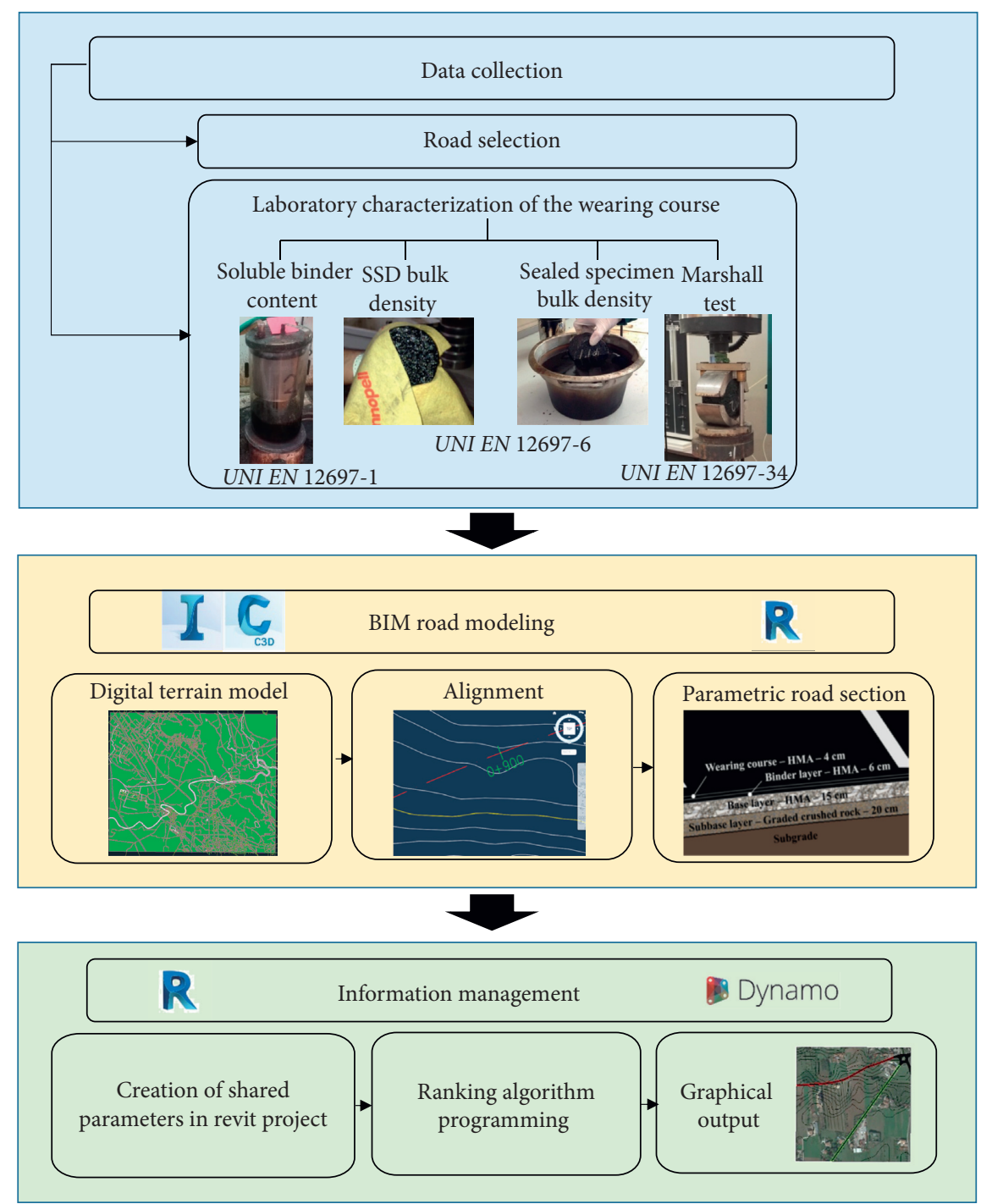

FIgURE 1: Methodology overview.

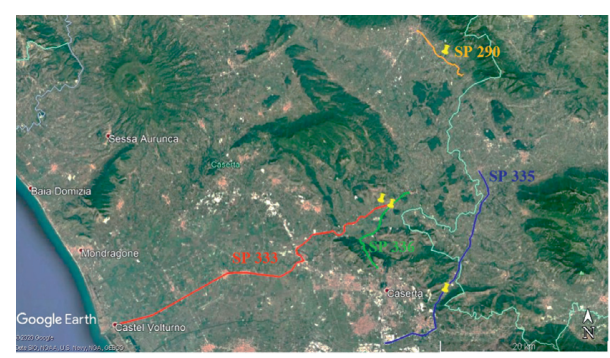

FIGURE 2: Aerial view of the study area that contains the analyzed road sections.

pavement, the application of BIM technology in the road design is not limited to the route design but can also reflect the pavement design and management information.

2.3. Information Management. Once the current state of the elements of the road network under analysis was correctly modelled and parameterized, a number of shared parameters to be associated with the road pavement materials were created to match the information contained in the database

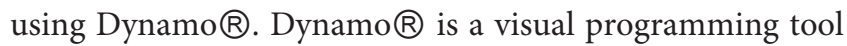

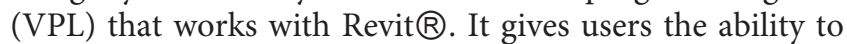
visually script behavior, define custom pieces of logic, and script using various textual programming languages. Dy-

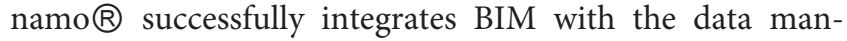
agement within the environment of a graphical algorithm editor. Users can create geometries and manipulate models in Revit $\AA$ or within Dynamo $\AA$ by coupling code blocks, which are programmed to execute a task assigned to them. The language in which the codes are scripted is Python $\circledast$.

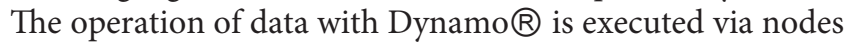

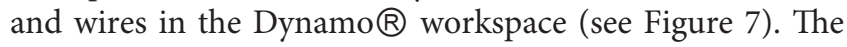
nodes consist of a script, which are assigned a task.

It can involve a very simple operation such as storing a number in a list, creating complex geometry, or manipulating imported data. With some exceptions, the majority of nodes are composed of five parts: (1) name of the node; (2) 


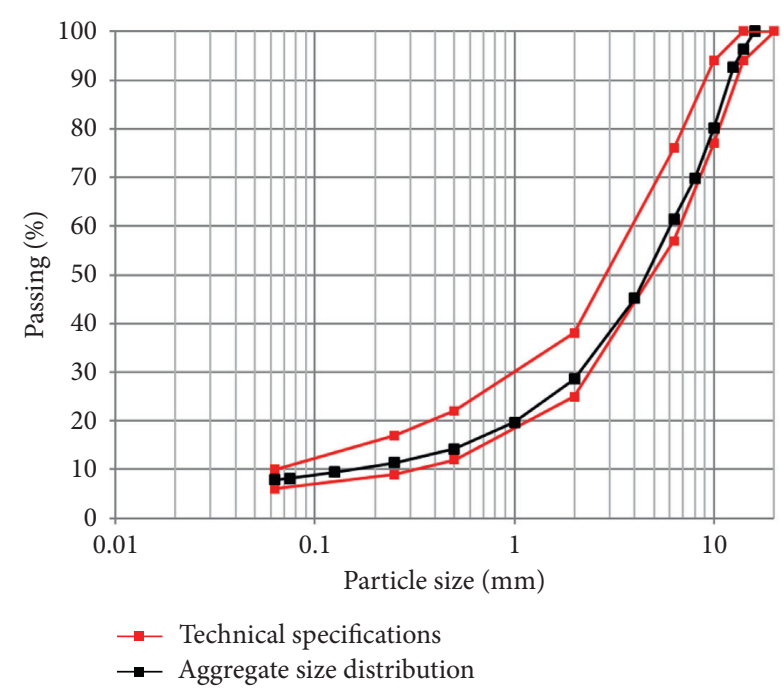

FIgURe 3: Aggregate size distribution and limits imposed by the technical specifications.

main body; (3) in- and out-ports where wires are connected; (4) data preview where primary results executed from the node can be previewed; and, (5) a lacing icon that indicates the lacing option specified for the matching list. The wires that connect the nodes transport data from one node to another.

The shared parameters used in this study were the road name, the road administration authority, the year in which the material was put in place during routine maintenance operations, and the physical and mechanical features of the wearing course mixtures, namely, bitumen content, air voids' percentage calculated with bulk specific gravity determined by means of the dimensional procedure, SSD procedure or sealed specimen procedure, and Marshall Stability.

The abovementioned shared parameters were then imported in the current project as materials' features. The remaining item to carry out was the importation of the database to assign values to the parameters of each material.

In order to do so, the material codes were exported to Excel with the programming flow reported in Figure 8 and then matched with the materials' names in the worksheet. The code block "Data.ExportExcel" (5) allowed creating a worksheet, whose file path, sheet name, and position of the exported data were defined, respectively, with the code blocks (4A), (4B), and (4C). The worksheet contained a list (4D) of materials' identifiers (3A) and names (3B) selected from the whole list of all the elements (2) of the materials' category (1) [38].

Once the material codes were matched with the corresponding information contained in the database, the resulting worksheet, whose excerpt is reported in Table 1 ,

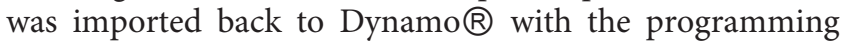
flow reported in Figure 9.

The code block "Data.ImportExcel" (3) was used to import a file object (2A) selected from a specific file path (1), whose name was specified (2B). Finally, the resulting list was transposed (4) into a list of lists, each corresponding to a column of the worksheet.

Then, the imported lists were associated with the corresponding parameters of the model elements. The specific code block that allowed the association was called "Element.SetParameterByName," and the inputs of which are as follows:

(1) The elements of the list to whom the values of the database shall be associated, namely, the material codes corresponding to the materials created in the Revit ${ }^{\circledR}$ project

(2) The parameter names and relative values read from the imported worksheet

The values to be assigned to each parameter for each wearing course were selected from the imported database with the programming flow reported in Figure 10.

Each item corresponding to a column of the database was selected from the imported lists (1), assembled in a new list (2), and then separated into sublists, each of them referring to a different road pavement material (3). Lastly, the average value of each set of measurements was calculated (4). Any empty cell of the given database was eliminated with the code block "List.Clean."

The abovementioned operations allowed for the visualization of the physical and mechanical features of the wearing course in the Revit model and the updating of the information once the input worksheet has been completed with new data. The visualization of the imported data in $\operatorname{Revit} \circledast$ is visible in the material parameters' interface, as shown in Figure 11.

Once the model was completed with information regarding the mechanical and physical characterization of the materials, the implementation of a ranking algorithm to evaluate the durability of the wearing course material based on the material characterization was performed.

When road performance indicators and their time evolution are not available to the road administrator, it is still possible to program routine maintenance basing on the physical and mechanical features of the wearing course that were assessed after the paving operations.

The deterioration rate of surface performance indicators depends strongly on a series of physical and mechanical properties of the bituminous mixture. In particular, for a flexible pavement, air voids, bitumen content, and Marshall Stability play a fundamental role in defining the ability of the layer to carry heavy loads without exhibiting excessive permanent deformations over time [39]. It is therefore possible to combine these parameters according to linear functions to evaluate the overall conditions of the wearing course.

In the present study, a series of positive and negative indicators was established to calculate a score for each of the analyzed wearing courses. Each indicator was defined by a condition regarding the result of a control test that was conducted on the bituminous mixture sampled from the mixture produced for the laying of the wearing course in comparison to the specific technical standard requirements of each road. 
TABLE 1: Excerpt of the worksheet containing survey data of the road pavement materials.

\begin{tabular}{|c|c|c|c|c|c|c|c|c|}
\hline Year & Report $n^{\circ}$ & Authority & Road name & $\begin{array}{l}\text { Bitumen } \\
\text { content }(\%)\end{array}$ & $\begin{array}{c}\text { Air voids } \\
\text { (paraffin) (\%) }\end{array}$ & $\begin{array}{l}\text { Air voids } \\
\text { (SSD) }(\%)\end{array}$ & $\begin{array}{c}\text { Air voids } \\
\text { (dimensional) }(\%)\end{array}$ & $\begin{array}{c}\text { Marshall } \\
\text { stability (daN) }\end{array}$ \\
\hline \multirow{6}{*}{2012} & \multirow{6}{*}{4968} & \multirow{6}{*}{ Province of Caserta } & \multirow{6}{*}{333} & 5.5 & 5.0 & & 10.62 & \\
\hline & & & & 5.5 & 5.0 & & 11.36 & \\
\hline & & & & & & 5.4 & 9.97 & 1066.0 \\
\hline & & & & & & 6.0 & 10.30 & 1220.0 \\
\hline & & & & & & 5.4 & 10.12 & 1160.0 \\
\hline & & & & & & 6.0 & 10.30 & 1123.0 \\
\hline \multirow{6}{*}{2011} & \multirow{6}{*}{4929} & \multirow{6}{*}{ Province of Caserta } & \multirow{6}{*}{336} & 6.1 & 6.5 & & 12.56 & \\
\hline & & & & 6.1 & 6.5 & & 10.73 & \\
\hline & & & & & & 7.9 & 13.33 & 1053.0 \\
\hline & & & & & & 7.8 & 11.96 & 1277.0 \\
\hline & & & & & & 7.7 & 11.00 & 1240.0 \\
\hline & & & & & & 6.8 & 10.18 & 1421.0 \\
\hline \multirow{6}{*}{2011} & \multirow{6}{*}{4938} & \multirow{6}{*}{ Province of Caserta } & \multirow{6}{*}{290} & 4.7 & 10.0 & & 14.76 & \\
\hline & & & & 4.7 & 10.0 & & 15.03 & \\
\hline & & & & & & & 14.36 & 1134.0 \\
\hline & & & & & & 11.5 & 13.81 & 1092.0 \\
\hline & & & & & & 11.6 & 15.47 & 884.0 \\
\hline & & & & & & 11.3 & 15.55 & 950.0 \\
\hline \multirow{6}{*}{2011} & \multirow{6}{*}{4944} & \multirow{6}{*}{ Province of Caserta } & \multirow{6}{*}{335} & 6.0 & 17.0 & & 16.18 & \\
\hline & & & & 6.0 & 17.0 & & 16.66 & \\
\hline & & & & & & 8.2 & 16.78 & 1020.0 \\
\hline & & & & & & 8.6 & 15.09 & 1150.0 \\
\hline & & & & & & 9.7 & 17.17 & 1056.0 \\
\hline & & & & & & 8.5 & 16.25 & 1144.0 \\
\hline
\end{tabular}

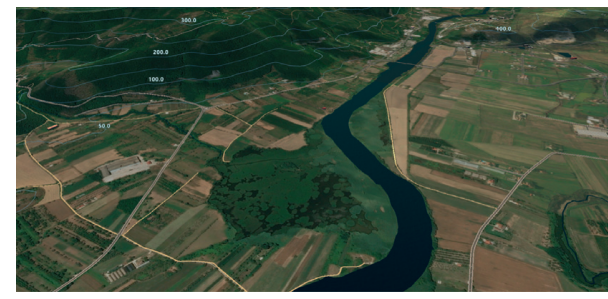

FiguRE 4: Infraworks digital terrain model.

Therefore, taking into account the technical standards of the bituminous mixtures for wearing course of the four considered road sections, a positive unitary score is assigned each time the bituminous mixture fulfills one of the conditions listed below:

(1) Bitumen content (BC) is in the range $4.5 \%-6.1 \%$ by the weight of the mixture

(2) Air voids determined by means of the dimensional procedure (AV) range between $3 \%$ and $8 \%$

(3) The difference between air voids determined by means of the sealed specimen and SSD procedure $(\Delta)$ is equal or lower than $1 \%$

Each time one of the first two conditions is not satisfied, a negative score proportional to the distance of the value from the lower or upper limit is calculated using equations (2) and (3), respectively:

$$
\begin{gathered}
\mathrm{NS}_{i, k}=\frac{P_{i, k}}{L_{i, l}}-1, \quad \text { if } P_{i, k}<L_{i, l}, \\
\mathrm{NS}_{i, k}=1-\frac{P_{i, k}}{L_{i, u}}, \quad \text { if } P_{i, k}>L_{i, u},
\end{gathered}
$$

where $\mathrm{NS}_{i, k}$ is the negative score due to the failure to fulfill the required $i$ th specification by the $k$ th wearing course mixture, $P_{i, k}$ is the value of the $i$ th parameter of the $k$ th mixture, and $L_{i, l}$ and $L_{i, u}$ are, respectively, the lower and upper limit of the range required for the $i$ th parameter.

Concerning the third condition of the list, since the difference between air voids determined with sealed and SSD procedure can be interpreted as a further indicator of lowdimensional air voids, the dissatisfaction of this condition did not penalize the material with additional negative score. The relative score was assigned through the following equation:

$$
\mathrm{PS}_{\Delta, k}= \begin{cases}1, & \text { if } \Delta_{k} \leq \Delta_{\max } \\ 0, & \text { if } \Delta_{k}>\Delta_{\max }\end{cases}
$$

where $\mathrm{PS}_{\Delta, k}$ is the positive score (null at most) resulting from parameter $\Delta$ for the $k$ th bituminous mixture, $\Delta_{k}$ is the difference between air voids determined with the sealed specimen and SSD procedure of the $k$ th mixture, and $\Delta_{\max }$ is the maximum acceptable difference. 


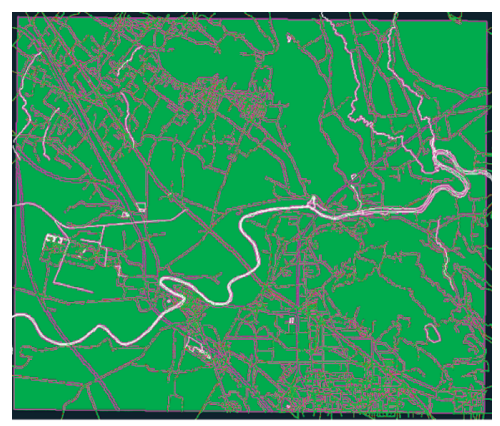

(a)

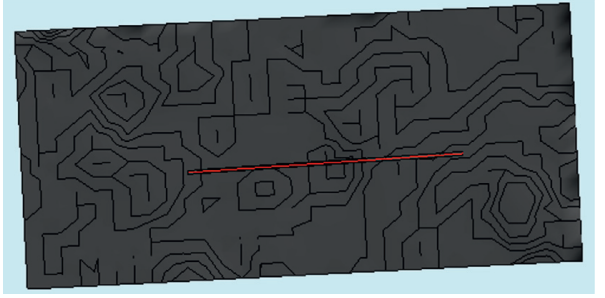

(b)

Figure 5: (a) Civil 3D Surface. (b) Topography surface and layout of the road section boundary in Revit.

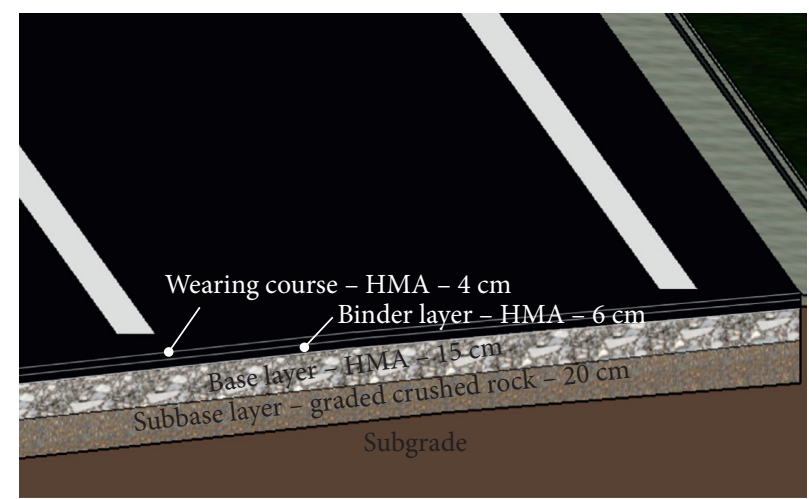

Figure 6: 3D cross section of the road pavement as displayed in the Revit model.

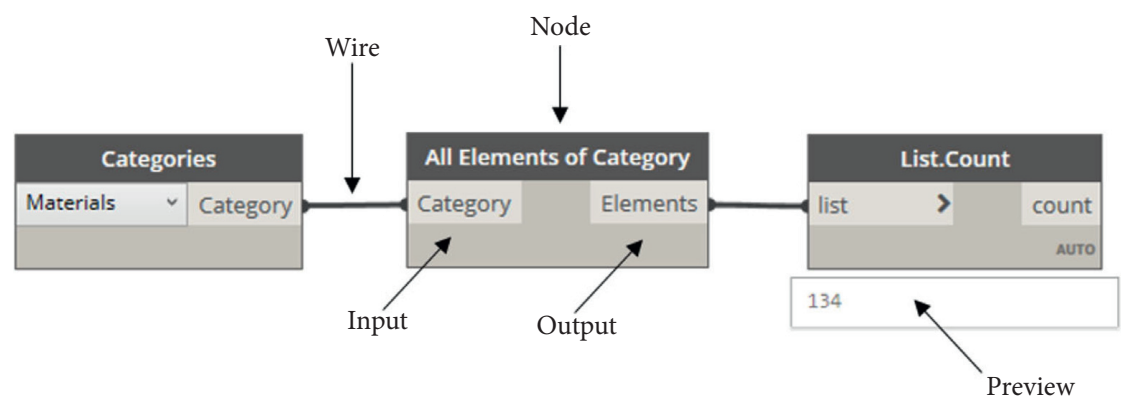

FIGURE 7: Structure of Dynamo visual programming language.

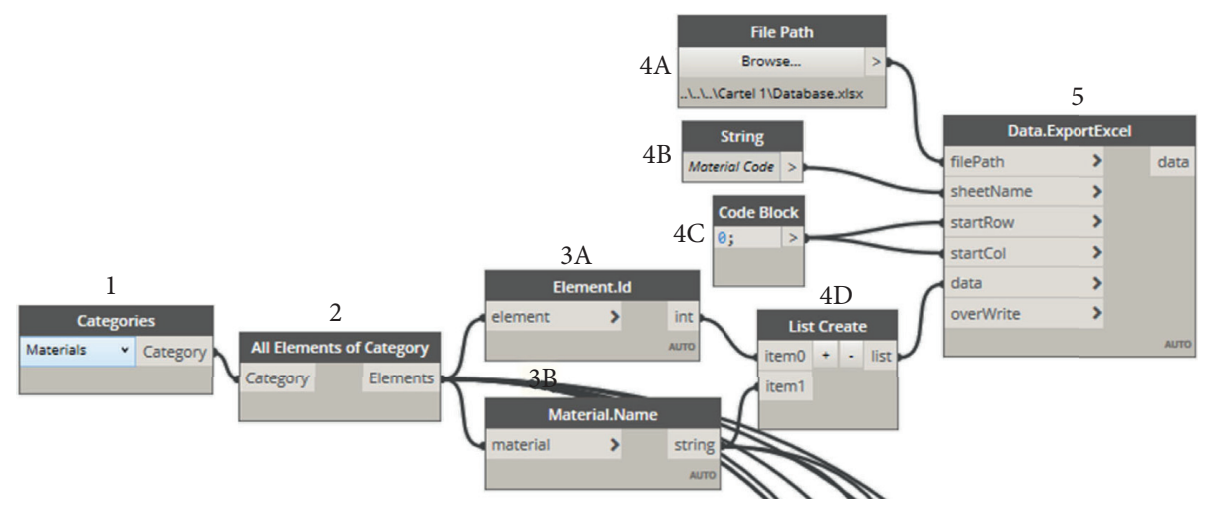

Figure 8: Exporting materials' codes to Excel. 


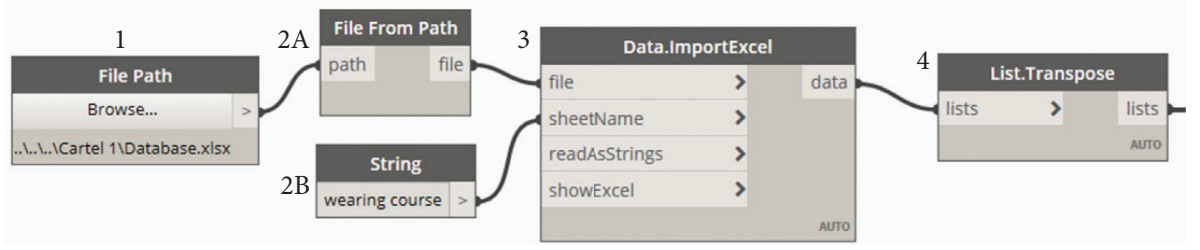

Figure 9: Importing a list to Dynamo from the Excel worksheet.

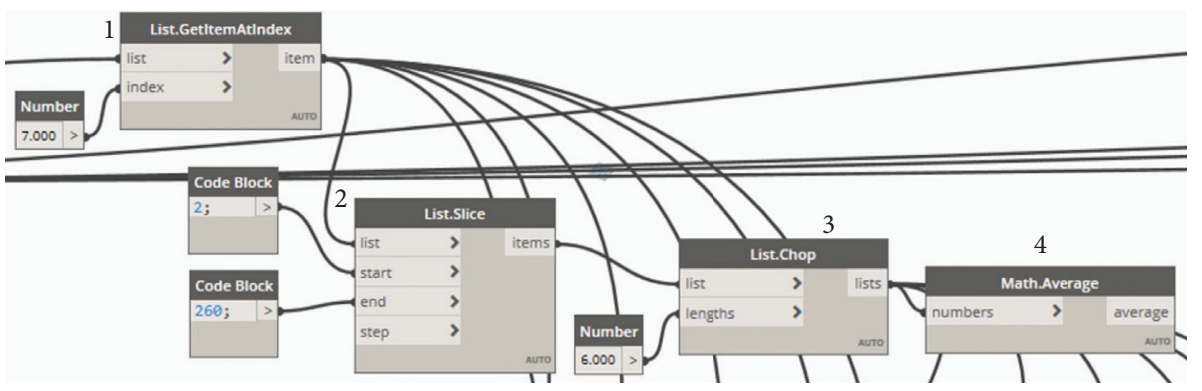

FIGURE 10: Selection and average of the lists of measurement for the association to the model parameters.

Lastly, the values of Marshall Stability (MS) allowed assigning a positive score, equal or greater than 1 , when they were equal or exceeded the minimum MS requirement, or a negative score when they failed to fulfill the requirement. The score proportional to the measured value of Marshall Stability was determined with following equations:

$$
\begin{aligned}
& \mathrm{PS}_{\mathrm{MS}, k}=\frac{\mathrm{MS}_{k}}{\mathrm{MS}_{\text {min }}}, \quad \text { if } \mathrm{MS}_{k} \geq \mathrm{MS}_{\text {min }}, \\
& \mathrm{NS}_{\mathrm{MS}, k}=\frac{\mathrm{MS}_{k}}{\mathrm{MS}_{\text {min }}}-1, \quad \text { if } \mathrm{MS}_{k}<\mathrm{MS}_{\text {min }},
\end{aligned}
$$

where $\mathrm{PS}_{\mathrm{MS}, k}$ and $\mathrm{NS}_{\mathrm{MS}, k}$ are, respectively, the positive and negative scores assigned to the $k$ th mixture as a consequence of the MS value, $\mathrm{MS}_{\text {mix }}$ is the determination of Marshall Stability of the $k$ th bituminous mixture for wearing course, and $\mathrm{MS}_{\min }$ is the minimum requirement of MS to comply with the technical specifications.

Figure 12 summarizes the linear functions that were implemented to assign a score to each wearing course solution based on the laboratory physical and mechanical characterization of the sample obtained from the wearing course laying.

The flow diagram of the procedure synthesized above and the ranking criteria are shown in Figure 13.

\section{Results and Discussion}

The algorithm in Figure 13 was automatized and integrated in the digital model of the road network by interfacing the worksheet that collects data with Dynamo $®$ for Revit $₫$.

Each of the scoring criteria that were described in the present section was individually programmed, and then, the overall score of each wearing course was calculated. As an example, the verification of $\mathrm{BC}$ was implemented as follows.

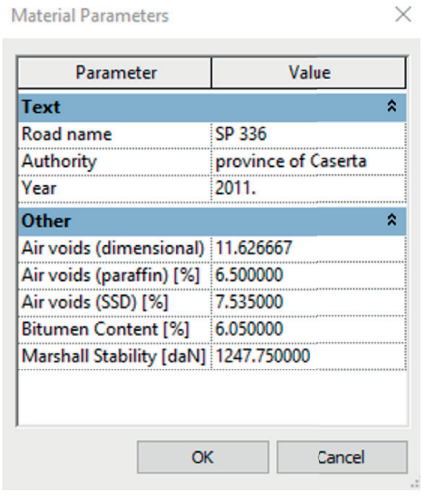

FIGURE 11: Example of material parameters in the Revit model after the association of worksheet data to the model using Dynamo.

Firstly, the inclusion of BC in the range $4.5 \%-6.1 \%$ was verified through the algorithm reported in Figure 14. The average bitumen content of the mixture was confronted with the lower (1) and upper (2) limit imposed by the technical specifications, and the results were expressed by Boolean variables that were used as an input to an "if" block (3).

The output of the "if" block was set equal to one when the variable matched with the specifications; otherwise, a negative score was calculated according to equation (1) or (2), as expressed by the group of blocks (4) and (5), respectively. The outcome of the two "if" blocks was incorporated into a list (6), and the final score for each road surface material was selected as the minimum item of the list (7).

A similar programming flow was implemented for all evaluation criteria in order to replicate the logical structure of Figure 13.

Once the overall score of each bituminous mixture was determined by summing the score of each evaluation criteria, the last step of the algorithm was to highlight the road 


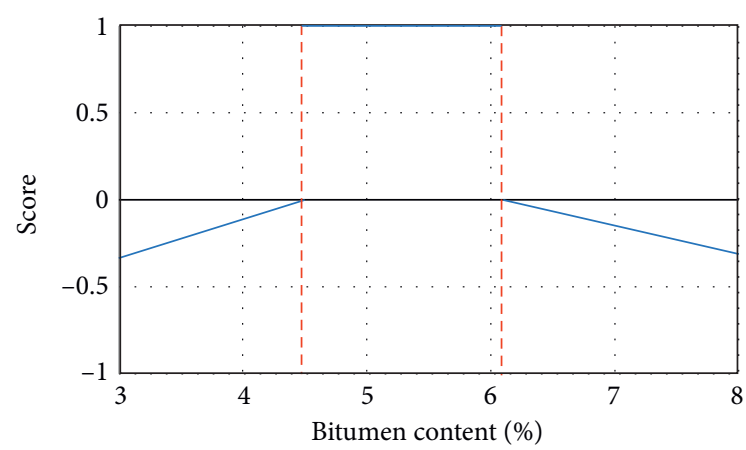

(a)

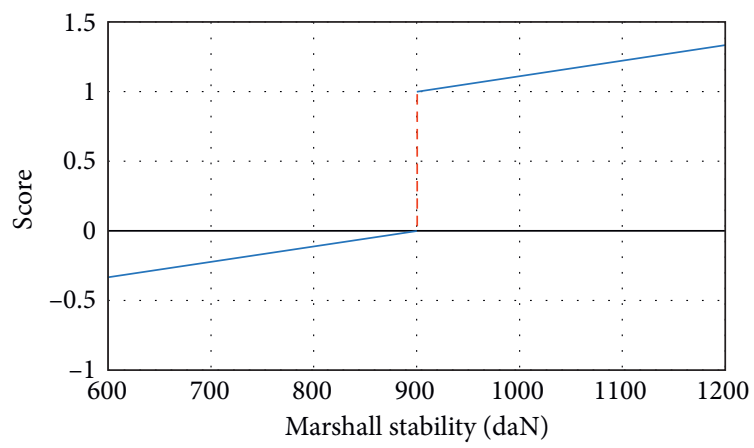

(c)

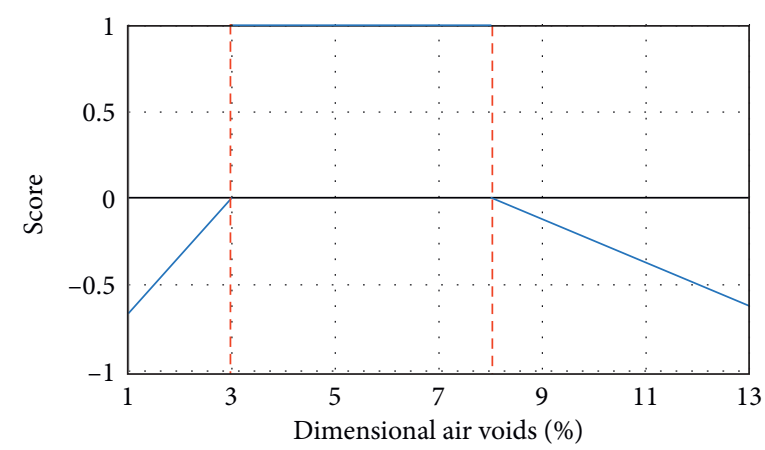

(b)

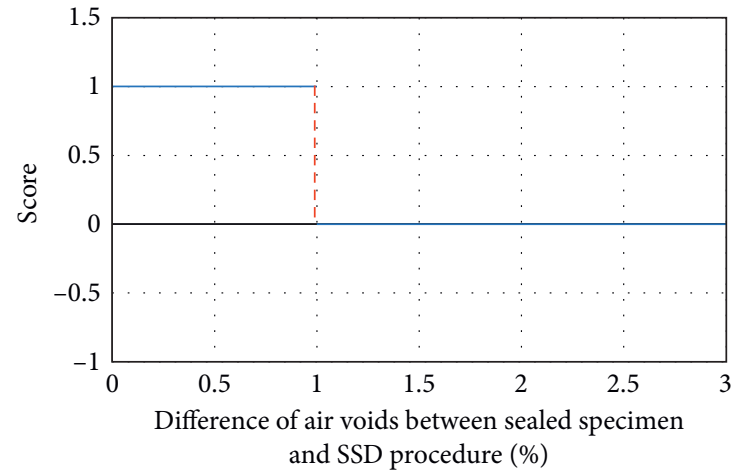

(d)

FIGURE 12: Graphic representation of the positive and negative score assigned to the bituminous mixtures based on the bituminous mixtures' sample characterization.

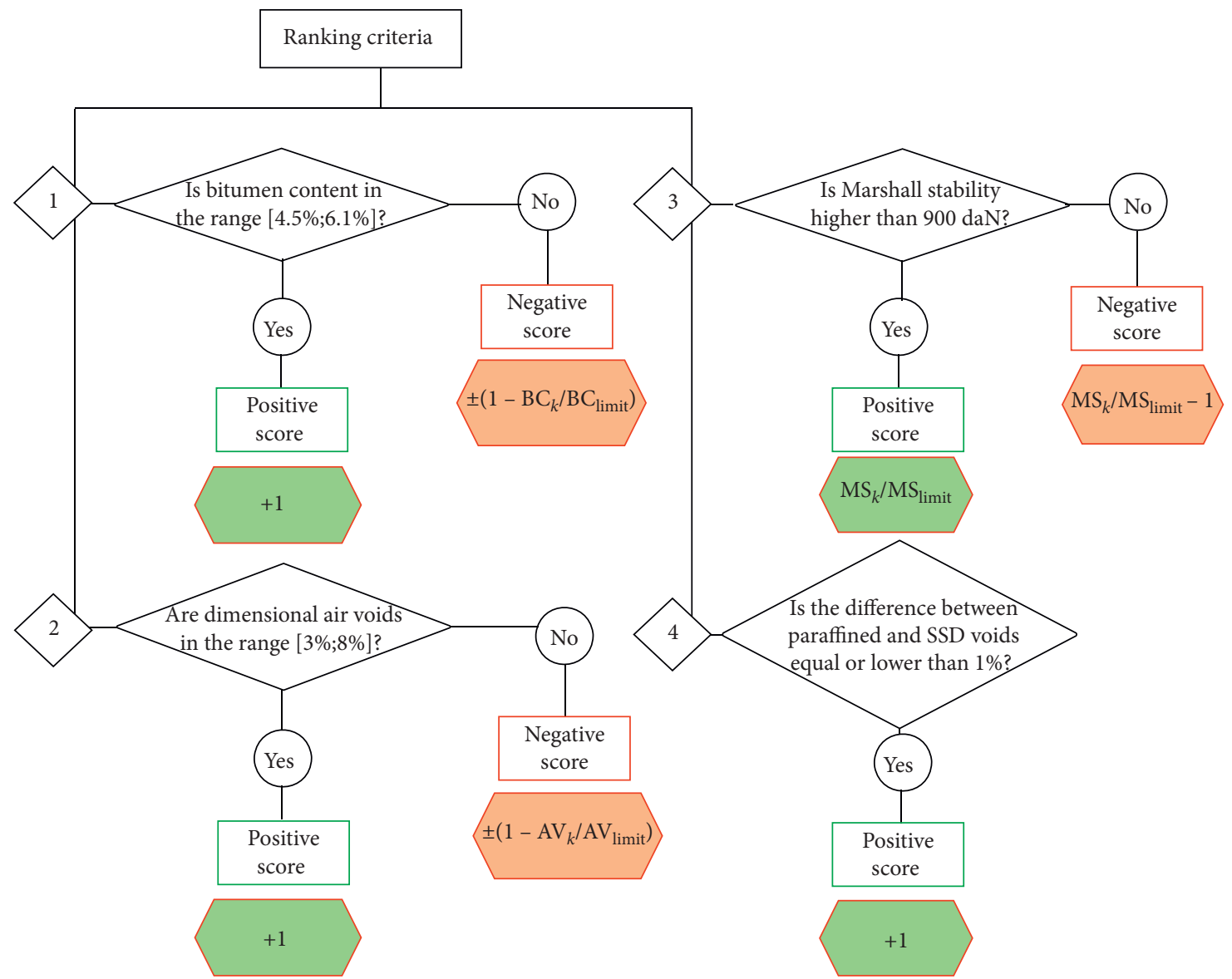

FIGURE 13: Flow diagram of the ranking procedure and ranking criteria. 


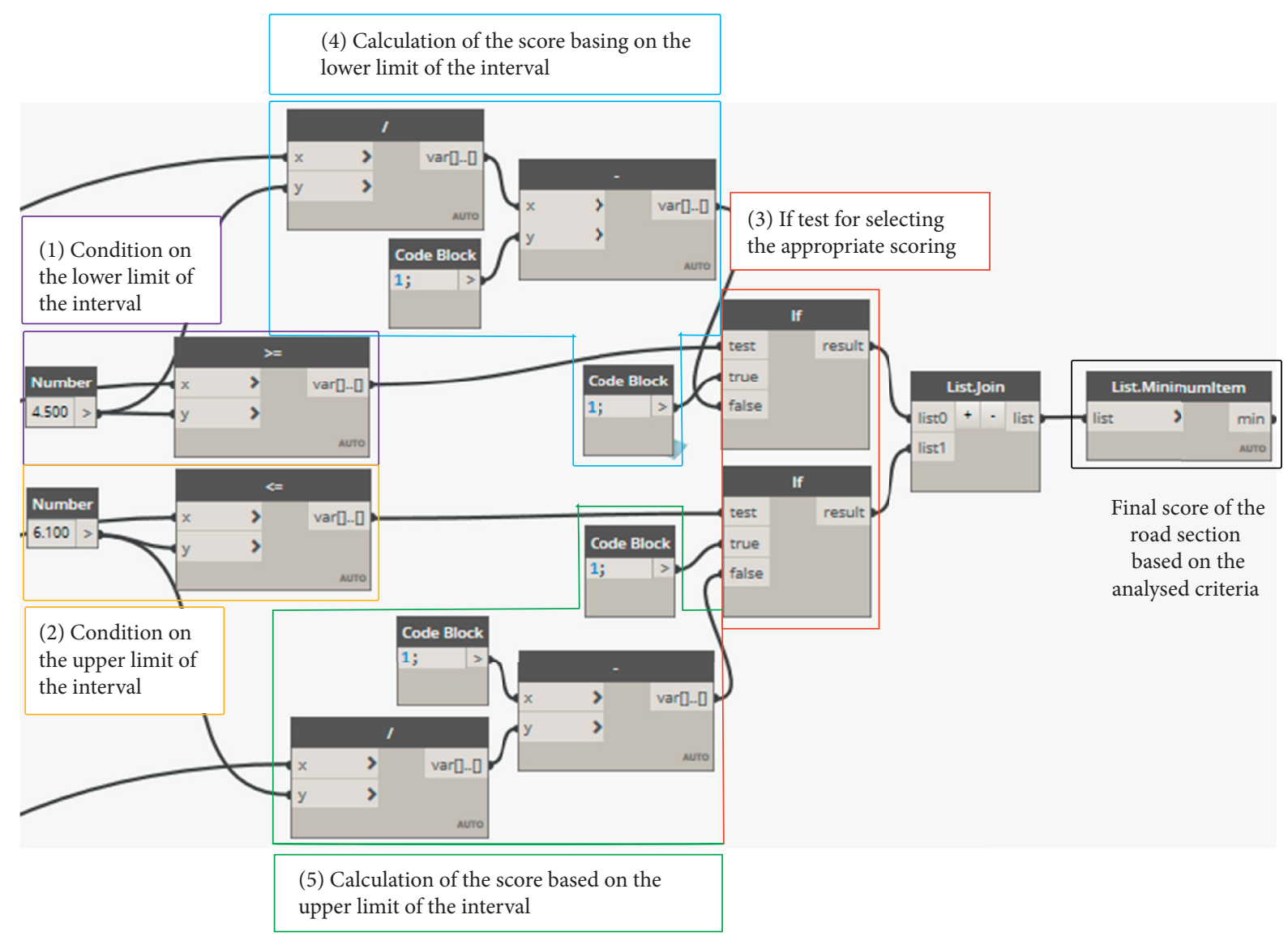

FIGURE 14: Bitumen content verification and scoring of the road surfaces.

surface having the worst performance, as shown in Figure 15.

The list containing the overall scores of the evaluated road surfaces (1) was confronted with the list of identification codes of the corresponding elements of the model (3) using the code block "List.FilterByBoolMask" (4). This operation filters the list of elements' codes by looking up for corresponding indices in a list of Boolean variables. In the present study, the list of Boolean variables was obtained by identifying the road surface with the minimum score (2). Lastly, the element code that satisfied condition (2) was highlighted in the model element with the color red (5) by using the code block "Element.OverrideColorInView" (6).

The application of the algorithm discussed in the section above generated a calculated score for each bituminous mixture for wearing course belonging to the road sections under consideration.

The overall scores and colours reported in Figure 16 provide the final ranking and predicted life of the surface layers of the four roads under analysis at each year, regardless of whether routine maintenance operations were performed on certain sections of the road. Colours range from green, which corresponds to the surface layer with the longest predicted life, to red, which corresponds to the layer that will probably require routine maintenance before all the others since the properties of the bituminous mixtures do not satisfy all the technical specification requirements.
In Figure 16(a), it is evident that the SP336 in year 2011 underwent a maintenance operation that showed the highest cumulative score in terms of compliance with the technical specifications, whereas the other three roads seem to have unsatisfactory physical and mechanical properties after routine maintenance operations.

Therefore, as the algorithm suggests, the SP335, SP333, and SP290 required additional routine maintenance in year 2012, and as a result, their cumulative score was modified (see Figure 16(b)); nevertheless, only the SP335 and SP333 resulted in an actual improvement of their predicted life, and thus, they should not require any additional maintenance in year 2013.

In year 2013, as shown in Figure 16(c), maintenance operations were actually performed on both the SP290 and SP335, despite the fact that the SP335 had the highest score among the road sections under consideration that could depend on exceptional events that are not directly linked to the poor physical and mechanical features of the wearing course. The SP290 was again found to be deviating the most from the technical specification requirements after the maintenance operations in year 2013 (see Figure 16(c)).

For each of the years under consideration, the output of the algorithm consists of the colouring of the road surface boundary that totals the lowest score, taking into account the following: bitumen content, dimensional percentage air voids, difference between sealed specimen and SSD 


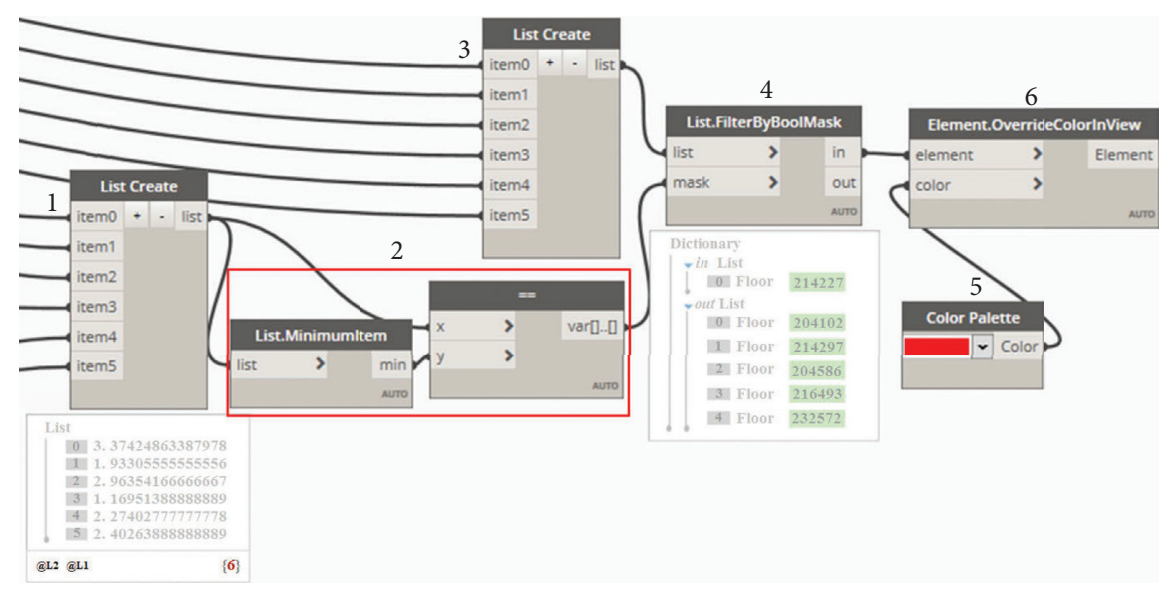

FIgURE 15: Selection and highlighting of the wearing course with the worst performance.

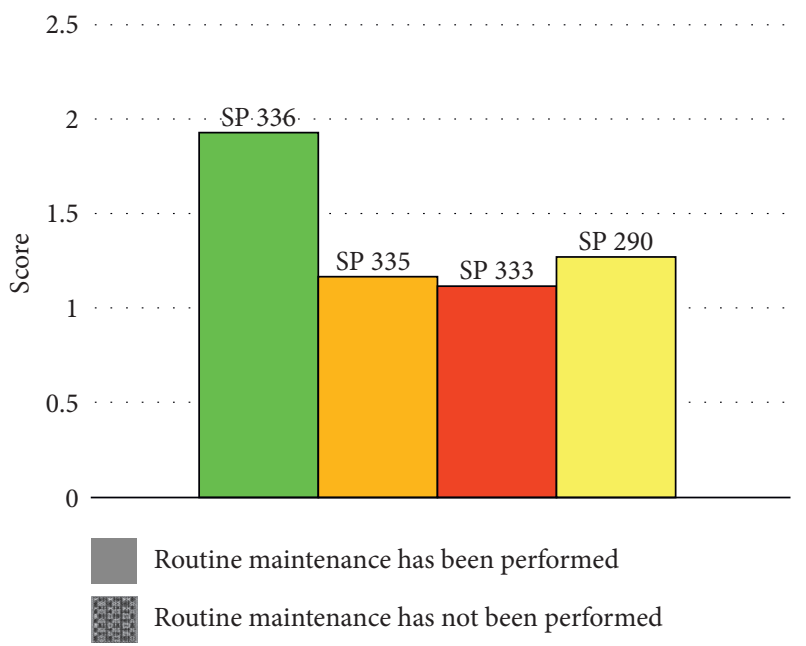

(a)

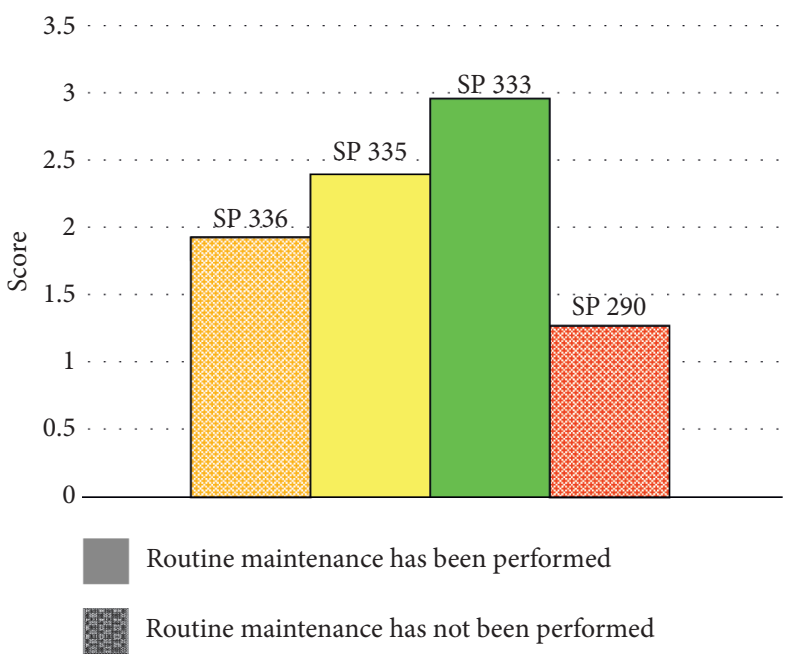

(b)

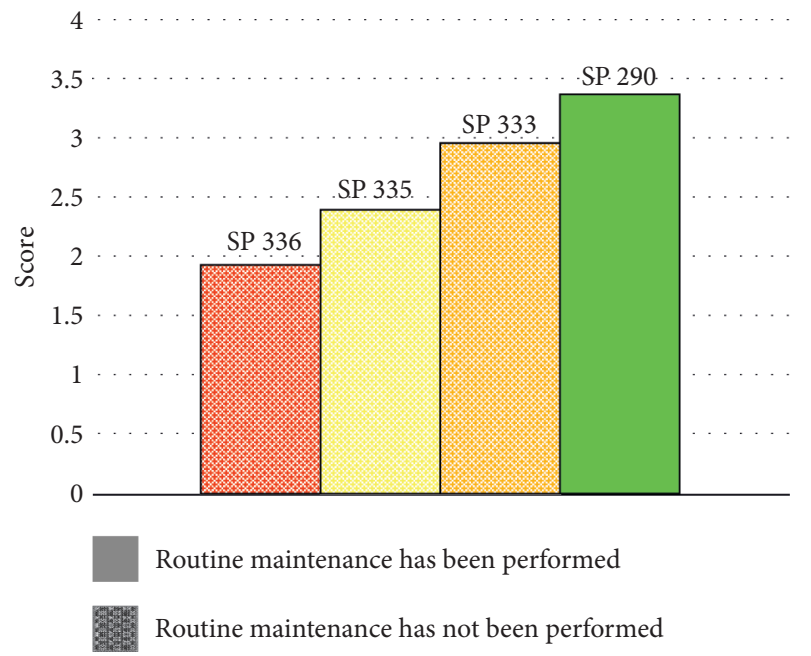

(c)

FIGURE 16: Overall score of the road section pavement condition. (a) Year 2011. (b) Year 2012. (c) Year 2013. 

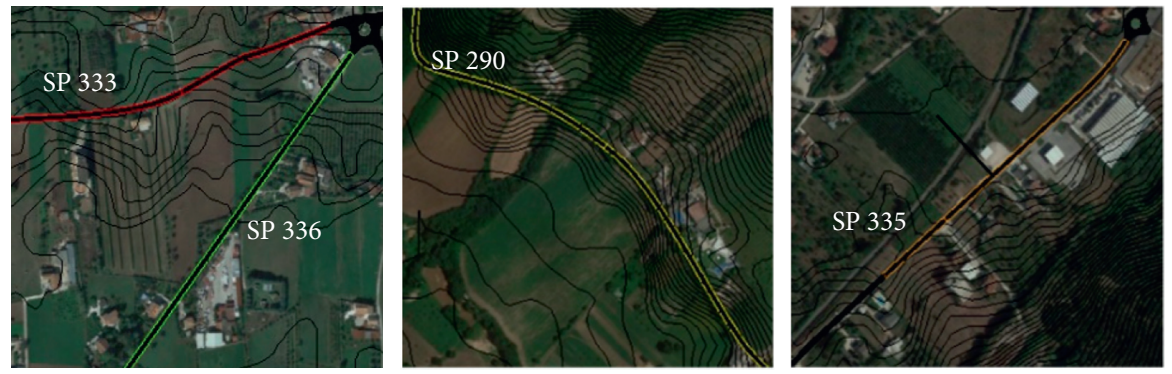

(a)
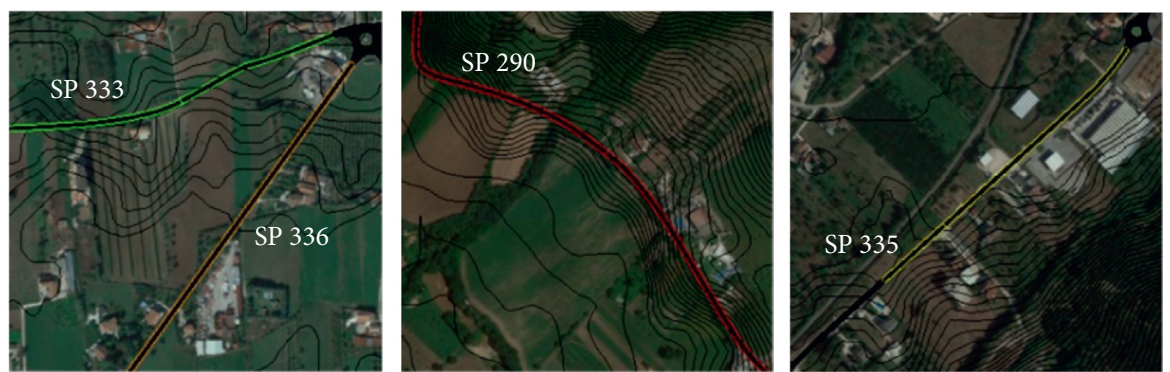

(b)
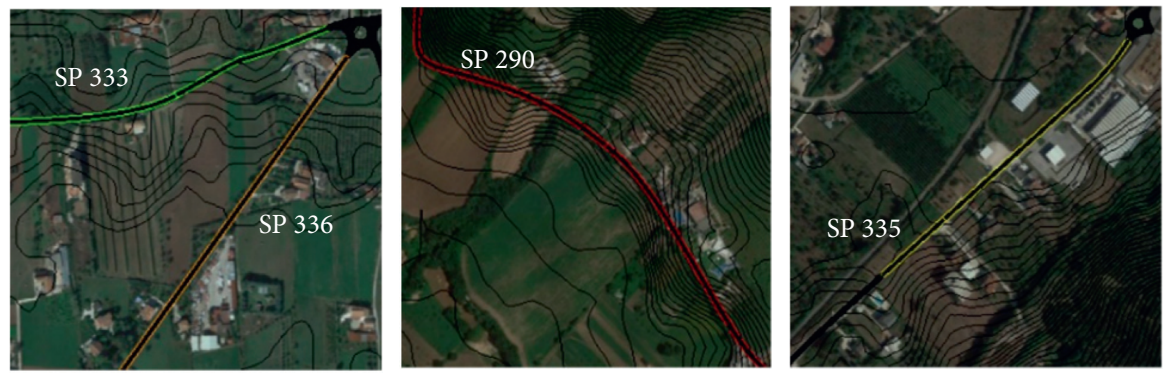

(c)

Figure 17: Dynamo algorithm output as displayed in Revit. (a) Year 2011. (b) Year 2012. (c) Year 2013.

percentage air voids, and Marshall Stability in comparison to the technical specifications for Italian road works.

The graphical output results as they appear in the Revit project are shown in Figure 17. In the case study under examination, the algorithm outlined all the considered road sections with different colours, depending on the cumulative score after the maintenance operations. For each of the considered years, the road with the poorest material quality is highlighted in red, while the others are coloured orange, yellow, and green, listed in the ascending order of bituminous mixture quality.

As shown in Figure 17, the main road SP333, in year 2011, and SP290, in years 2012 and 2013, are identified as the road surfaces that could possibly deteriorate faster than the others, due to the low physical and mechanical features of the bituminous mixtures for wearing course.

\section{Conclusions}

In conclusion, the methodology implemented here allowed

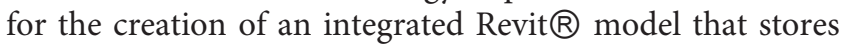
and analyzes data produced by the quality controls of the bituminous materials after laying and compaction.
Given the results of the main physical and mechanical tests that were carried out in the laboratory on bituminous mixtures' samples obtained from the mixtures adopted for the wearing course, they were associated with the parametric elements of the digital model using a Visual Programming

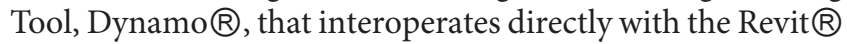
model.

Within the same programming environment, a ranking algorithm based on the available information regarding the materials' properties was developed; a series of positive and negative scores were calculated for each material based on the limits imposed by the technical specifications of the road administrations.

The applied methodology resulted in a dynamic model that updates its information package and modifies the output of the analysis every time the data worksheet is integrated with new test results. The execution of the algorithm directly interacts with the appearance of the road network model, giving the user, namely, the road administrator, an easy-to-read alert signal for a specific element of the road pavement structure.

The main advantages achieved through the adoption of a BIM process in the management of data arising from 
laboratory characterization for routine road maintenance can be listed as follows.

(1) Creation of a safe, interoperable model of the road network that is able to store and analyze useful data for the prediction of the service life of the pavement, also allowing the visualization of a 3D detailed model of the road structure

(2) Immediate verification of the compliance of the materials' features with the technical specifications

(3) Linking of a customized ranking algorithm for the hierarchization of routine maintenance to the $3 \mathrm{D}$ model of the road pavement, which requires minor changes when applied to a new project

The tool is intended not only to support the prioritization of any existing Pavement Management System that is currently adopted by administrations to plan maintenance operations on the road network but also to provide information as an alert system for identifying what does not work in maintenance operations.

The model could be further improved by integrating information about traffic volumes, traffic composition, environmental conditions, and more detailed data about all the materials composing the layers of the road package, in order to adjust the ranking algorithm so that it takes into consideration all the relevant factors that affect pavement life.

Moreover, the ranking algorithm could be integrated with a model intended for optimal routine maintenance schedule simulation that could help to save time in the elaboration of Gantt charts of the planned activities and keep track of the past operations.

In conclusion, BIM tools such as visual programming languages that interoperate with the main modeling software will allow any kind of algorithm implementation. For example, a more complex ranking algorithm could be implemented when monitoring data, such as distress analysis and performance indicators, are available. Eventually, uneven information could be condensed into a single multiobjective optimization model that could also consider cost evaluations and environmental impacts of the operations under exam.

\section{Data Availability}

The data used to support the findings of this study are available from the corresponding author upon request.

\section{Conflicts of Interest}

The authors declare that there are no conflicts of interest regarding the publication of this paper.

\section{Acknowledgments}

This research was developed within the Projects of National Interest-PRIN 2017 "Stone pavements. History, Conservation, Valorisation, and Design" (20174JW7ZL) financed by the Ministry of Education, University and Research (MIUR) of the Italian Government.

\section{References}

[1] P. Marcelino, M. D. Lurdes Antunes, and E. Fortunato, "Comprehensive performance indicators for road pavement condition assessment," Structure and Infrastructure Engineering, vol. 14, no. 11, pp. 1433-1445, 2018.

[2] S. S. Adlinge and A. K. Gupta, "Pavement deterioration and its causes," International Journal of Innovative Research and Development, vol. 2, no. 4, pp. 437-450, 2013.

[3] E. Kassem, E. Masad, R. Lytton, and A. Chowdhury, "Influence of air voids on mechanical properties of asphalt mixtures," Road Materials and Pavement Design, vol. 12, no. 3, pp. 493-524, 2011.

[4] S. Badeli, A. Carter, and G. Doré, "The importance of asphalt mixture air voids on the damage evolution during freeze-thaw cycles," in Proceedings of the Sixth-First Annual Conference of the Canadian Technical Asphalt Association, pp. 13-16, Canadian Technical Asphalt Association, Banff, AB, USA, November 2016.

[5] P. Cui, Y. Xiao, B. Yan, M. Li, and S. Wu, "Morphological characteristics of aggregates and their influence on the performance of asphalt mixture," Construction and Building Materials, vol. 186, pp. 303-312, 2018.

[6] F. Russo, S. A. Biancardo, A. Formisano, and G. Dell'Acqua, "Predicting percent air voids content in compacted bituminous hot mixture specimens by varying the energy laboratory compaction and the bulk density assessment method," Construction and Building Materials, vol. 164, pp. 508-524, 2018.

[7] R. Veropalumbo, N. Viscione, and A. Formisano, "Hot mix asphalt with fly ashes for dense-graded surface layers of rural roads," WIT Transactions on Ecology and the Environment, vol. 215, pp. 93-105, 2018.

[8] R. Veropalumbo, F. Russo, N. Viscione, and S. A. Biancardo, "Rheological properties comparing hot and cold bituminous mastics containing jet grouting waste," Advanced in Material Science and Engineering, vol. 2020, Article ID 8078527, 16 pages, 2020.

[9] T. Park, T. Kang, Y. Lee, and K. Seo, "Project cost estimation of national road in preliminary feasibility stage using BIM/ GIS platform," in Proceedings of the Computing In Civil And Building Engineering, pp. 423-430, ASCE Library, Orlando, FL, USA, June 2014.

[10] A. Tibaut, S. Pečnik, M. R. Korošec, K. Mihalic, and I. Zabreznik, "BIM-based parametric modeling of roads and Infrastructure objects," in Proceedings of the 32nd CIB W78 Conference, Eindhoven, The Netherlands, October 2015.

[11] H. T. Abdelwahab, "Intelligent design (4D, 5D and beyond) for road design and construction projects: two case studies," International Road Federation (IRF) Examiner, vol. 12, pp. 21-25, 2018.

[12] F. Abbondati, S. A. Biancardo, G. Sicignano, S. G. D. Oliveria, A. Tibaut, and G. D. Acqua, "BIM parametric modelling of a railway underpass," Ingegneria Ferroviaria, vol. 75, no. 6, pp. 443-459, 2020.

[13] S. A. Biancardo, N. Viscione, C. Oreto, R. Veropalumbo, and F. Abbondati, "BIM approach for modeling airports terminal expansion," Infrastructures, vol. 5, no. 5, p. 41, 2020.

[14] F. Abbondati, S. A. Biancardo, R. Veropalumbo et al., "Surface monitoring of road pavements using mobile crowdsensing technology," Measurement, vol. 171, Article ID 108763, 2021.

[15] S. Fabozzi, S. A. Biancardo, R. Veropalumbo et al., "I-BIM based approach for geotechnical and numerical modelling of a 
conventional tunnel excavation," Tunnelling and Underground Space Technology, vol. 108, Article ID 103723, 2021.

[16] G. Dell'Acqua, S. Guerra De Olivera, and S. A. Biancardo, "Railway-BIM: analytical review, data standard and overall perspective," Ingegneria Ferroviaria, vol. 11, pp. 901-923, 2018.

[17] S. A. Biancardo, N. Viscione, A. Cerbone, and E. Dessì, "BIMbased design for road infrastructure: a critical focus on modeling guardrails and retaining walls," Infrastructures, vol. 5, no. 59, 2020.

[18] M. Marzouk and A. Abdelaty, "BIM-based framework for managing performance of subway stations," Automation in Construction, vol. 41, pp. 70-77, 2014.

[19] T. Tschickardt and D. Krause, "BIM im verkehrswegebau am beispielprojekt, verfügbarkeitsmodell A 10/A 24," Bautechnik, vol. 96, no. 3, pp. 259-268, 2019.

[20] G. Bosurgi, C. Celauro, O. Pellegrino, N. Rustica, and S. Giuseppe, "The BIM (building information modeling)based approach for road pavement maintenance," Lecture Notes in Civil Engineering, vol. 48, pp. 480-490, 2020.

[21] M. Leone, A. D’Andrea, G. Loprencipe, G. Malavasi, and L. Bernardini, "Building information modeling (BIM): prospects for the development of railway infrastructure industry," in Proceedings of the Conference: 1st AIIT International Congress on Transport Infrastructure and Systems, pp. 547-554, Rome, Italy, 2017.

[22] B. Sankaran, G. Nevett, W. J. O'Brien, P. M. Goodrum, and J. Johnson, "Civil integrated management: empirical study of digital practices in highway project delivery and asset management," Automation in Construction, vol. 87, pp. 84-95, 2018.

[23] F. Tang, T. Ma, Y. Guan et al., "Parametric modeling and structure verification of asphalt pavement based on BIMABAQUS," Automation in Construction, vol. 111, Article ID 103066, 2020.

[24] F. Tang, T. Ma, J. Zhang et al., "Integrating three-dimensional road design and pavement structure analysis based on BIM," Automation in Construction, vol. 113, Article ID 103152, 2020.

[25] S. M. Bazlamit, H. S. Ahmad, and T. I. A.-S. Al-Suleiman, "Pavement maintenance applications using geographic information systems," Procedia Engineering, vol. 182, pp. 83-90, 2017.

[26] W. Chen, J. Yuan, and M. Li, "Application of GIS/GPS in Shanghai Airport pavement management system," Procedia Engineering, vol. 29, pp. 2322-2326, 2012.

[27] R. Heikkilä and M. Marttinen, "Development of BIM based rehabilitation and maintenance process for roads," in Proceedings of the 30th International Symposium on Automation and Robotics in Construction and Mining (ISARC 2013): Building the Future in Automation and Robotics, vol. 30, p. 1, Montreal, Canada, August 2013.

[28] A. Bae, D. Lee, and B. Park, "Building information modeling utilization for optimizing milling quantity and hot mix asphalt pavement overlay quality," Canadian Journal of Civil Engineering, vol. 43, no. 10, pp. 886-896, 2016.

[29] A. Costin, A. Adibfar, H. Hu, and S. S. Chen, "Building information modeling (BIM) for transportation infrastructure-literature review, applications, challenges, and recommendations," Automation in Construction, vol. 94, pp. 257-281, 2018.

[30] Ministero delle Infrastrutture e dei Trasporti, Decreto Ministeriale Numero 560 del 01/12/2017, Ministero delle Infrastrutture e dei Trasporti, Rome, Italy, 2018.
[31] SpA, ANAS, Capitolato Speciale D'appalto - Norme Tecniche, Azienda Nazionale Autonoma delle Strade, Roma, Italy, in Italian, 2016.

[32] UNI EN 12697-1, Bituminous Mixtures-Test Methods for Hot Mix Asphalt-Part 1: Soluble Binder Content, British Standard Institute, London, UK, 2019.

[33] UNI EN 12697-30, Bituminous Mixtures-Test Methods-Part 30: Specimen Preparation by Impact Compactor, British Standard Institute, London, UK, 2019.

[34] UNI EN 12697-34, Bituminous Mixtures-Test Methods-Part 34: Marshall Test, British Standard Institute, London, UK, 2012.

[35] UNI EN 12697-8, Bituminous Mixtures-Test Methods-Part 8: Determination of Void Characteristics of Bituminous Specimens, British Standard Institute, London, UK, 2019.

[36] UNI EN 12697-5, Bituminous Mixtures-Test Methods-Part 5: Determination of the Maximum Density, British Standard Institute, London, UK, 2019.

[37] UNI EN 12697-6, Bituminous Mixtures-Test Methods for Hot Mix Asphalt-Part 6: Determination of Bulk Density of Bituminous Specimens, British Standard Institute, London, UK, 2012.

[38] S. A. Biancardo, C. Oreto, N. Viscione, and F. Russo, "BIM approach for smart infrastructure design and maintenance operations," Transportation Systems For Smart, Sustainable, Inclusive And Secure Cities, 2020.

[39] R. Veropalumbo, F. Russo, N. Viscione, S. A. Biancardo, and O. Cristina, "Investigating the rheological properties of hot bituminous mastics made up using plastic waste materials as a filler," Construction and Building Materials, vol. 270, Article ID 121394, 2021. 